\title{
Transformando corporalidades: Desbordes a la normalidad pedagógica
}

\section{Transformando corporalidades: transborbando a normalidade pedagógica}

\section{Transforming corporealities: beyond the pedagogical normality}

\author{
Graciela B. Alonso ${ }^{1}$ \\ Ruth Zurbriggen ${ }^{2}$
}

\begin{abstract}
RESUMEN
En este escrito reflexionaremos acerca de interpelaciones que corporalidades dislocadas de la ostensiva heteronormatividad realizan a las instituciones educativas, abriendo posibilidades para estirar y desbordar los límites epistemológicos y habilitar acciones pedagógicas y políticas en su interior. Las especulaciones que propondremos están situadas en perspectivas político epistemológicas feministas, queer y decoloniales, engarzadas con y entre nuestras prácticas en el activismo feminista y en nuestro trabajo en el campo de la formación docente en instituciones educativas públicas. El texto consta de tres partes. En la primera, configurada como una breve genealogía, nos detendremos en aportes del feminismo radical, en tanto abrevamos de ellos para politizar nuestra mirada del mundo y sus relaciones. Lo hacemos sin rehuir algunas menciones críticas que mereció esta perspectiva feminista. En la segunda, traeremos líneas de pensamiento construidas a partir de un proyecto de extensión: Por una educación pública antidiscriminatoria, no androcéntrica, no sexista, no heterosexista; de un trabajo de investigación: Aproximaciones al estudio del movimiento sexo-genérico en Argentina; y de intervenciones institucionales desarrolladas en la Universidad Nacional del Comahue y en el Instituto de Formación Docente n. ${ }^{\circ} 12$ de Neuquén. En la tercera, proyectamos algunos interrogantes en la búsqueda constante
\end{abstract}

DOI: $10.1590 / 0104-4060.36467$

1 Universidad Nacional de Comahue. Neuquén, Neuquén Province, Argentina. Area Centro Este. Perito Moreno, 851 (8300) Neuquén, Argentina.

2 Universidad de Neuquén. Neuquén, Neuquén Province, Argentina. Area Centro Este. Perito Moreno, 851 (8300) Neuquén, Argentina. 
por dinamitar las ficcionales fronteras de la heteronormatividad en las aulas, para una pedagogía otra, para una pedagogía transgresora al decir de Deborah Britzman.

Palabras claves: feminismos; heteronormatividad; corporalidades; formación docente; pedagogía otra.

\title{
RESUMO
}

Neste texto realizaremos reflexões sobre as interpelações que as corporalidades deslocadas da ostensiva heteronormatividade realizam sobre as instituições educacionais, criando possibilidades para distender e transbordar os limites epistemológicos, além de possibilitar ações pedagógicas e políticas em seu interior. As especulações que propomos neste texto estão situadas nas perspectivas político-epistemológicas feministas, queer e anticoloniais, entrelaçadas com/entre nossas práticas no ativismo feminista e em nosso trabalho no campo da formação docente em instituições educacionais públicas. O texto é composto por três partes. Na primeira, configurada como uma breve genealogia, iremos nos deter nas questões do feminismo radical, abreviando a exposição para politizar nosso olhar sobre o mundo e suas relações, o que fazemos sem deixar de mencionar algumas críticas a esta perspectiva feminista. $\mathrm{Na}$ segunda, traremos reflexões construídas a partir de um projeto de extensão intitulado Por una educación pública antidiscriminatoria, no androcéntrica, no sexista, no heterosexista; além de uma pesquisa intitulada Aproximaciones al estudio del movimiento sexo-genérico en Argentina e intervenções institucionais desenvolvidas na Universidad Nacional del Comahue e no Instituto de Formación Docente n. ${ }^{\circ}$ 12 de Neuquén. Na terceira parte, interrogamos sobre uma busca constante por dinamitar as fronteiras fictícias da heteronormatividade nos cursos de formação, para pensarmos uma pedagogia outra ou uma pedagogia transgressora, segundo Deborah Britzman.

Palavras-chave: feminismos; heteronormatividade; corporalidades; formação docente; pedagogia outra.

\begin{abstract}
In this paper we will reflect upon the interpellations which dislocated corporealities from ostensive heteronormativity perform in relation to educational institutions, opening possibilities to stretch and overflow epistemological limits and to enable pedagogical and political actions inside them. These speculations are grounded on queer and postcolonial epistemological political feminist perspectives, linked with and amongst our practices in feminist activism, in addition to our work in the field of teacher training in
\end{abstract}


institutions of public education. This paper consists of three parts. In the first one, configured as a brief genealogy, we focus on the contributions of radical feminism, since we are nourished by them in order to politicize our gaze of the world and of their relationships. In this section, we do not avoid mentioning some critical remarks that this feminist perspective deserves. In the second part, we bring up some lines of thought formulated in an extension project entitled Concerning anti-discriminatory, non-androcentric, non-sexist, non-heterosexist public education. This extension project is itself part of the research project Approaches to the study of sex-gender movements in Argentina and of some institutional interventions developed at the National University of Comahue and the Institute of Teacher Education n. 12 of Neuquén. Finally, in the last and third section we propose some critical questions oriented by our steady intention of exploding the fictional boundaries of heteronormativity in classrooms towards "another" pedagogy, that is, a transgressive pedagogy, like Deborah Britzman says.

Keywords: feminism; heteronormativity; corporealities; teacher education; another pedagogy.

\section{La radicalidad feminista: lo personal es político - corpopolítica}

"La genealogía no es la historia de los eventos, sino la investigación de las condiciones de emergencia de aquello que es considerado como historia: un momento de emergencia no pasa, en última análisis, de una fabricación" (Judith Butler).

Los años 1960 se caracterizan por una intensa y contestataria agitación política. El sistema democrático mostraba su rostro clasista, sexista, imperialista, racista, eurocéntrico y esto trajo la formación de una Nueva Izquierda junto con el surgimiento en cadena de movimientos a favor de derechos civiles, estudiantiles, pacifistas y feministas. El Movimiento de Liberación de la Mujer ${ }^{3}$ resulta de una reacción al papel subsidiario al que relega a las mujeres el movimiento antisistema de entonces.

Las feministas, hartas de señalar la jerarquización de las agendas políticas en las luchas que se venían librando, generan organizaciones autónomas; a este movimiento - que tuvo en su interior distintas expresiones - se lo conoce

3 El paraguas que sostiene el nombrar en singular muestra la referencia a una concepción homogeneizadora, universalista y excluyente que bajo la opresión de género pretende igualar a todas las mujeres, soslayando así las diversas diferencias y desigualaciones existentes. 
como feminismo radical. La proclama lo personal es político pasará a ser su gran programa de acción. Enfocarse en la esfera privada significa una verdadera revolución copernicana para la teoría y el movimiento feminista de los 1960 y 1970. Para esta corriente, los espacios de dominación patriarcal serán también los espacios hasta entonces considerados personales y privados, se buscará reflexionar y describir cuáles son los intrincados dispositivos con los que los sistemas de poder se producen y reproducen, claro está, para transformarlos deslegitimando el entramado conceptual que promueven esos pactos patriarcales y con ello redefinir la praxis política. En este entramado surge la organización de los grupos de autoconciencia para: el rescate de las voces de las mujeres, las reflexiones sobre las experiencias de vida, el paso de intereses individuales a lo colectivo. Un insistente activismo participativo, no jerárquico, con audaces y espectaculares intervenciones públicas será el motor fundamental para comprender una estructura de poder capaz de ser teorizada y conceptualizada.

Esta corriente toma al cuerpo como el locus de opresión de las mujeres; reivindica la sexualidad a la que considera una construcción política y hace una crítica a la heterosexualidad obligatoria; apuesta por el aborto libre y el derecho a la maternidad voluntaria; redefine la política y las formas de construir poder; denuncia la violencia patriarcal; promueve el combate al androcentrismo en todos los ámbitos y denuncia que la relación entre los sexos es siempre política. El concepto de patriarcado adquiere especial centralidad, busca la abolición de la dominación masculina y sus formas de definición, producción y concepción del conocimiento. Alicia Puleo sostiene que el patriarcado como sistema político es una respuesta de las feministas radicales a las posiciones de izquierda que sostenían que "el problema de la mujer" acabaría con la supresión del capitalismo (PULEO, 2007, p. 42).

Sin embargo, la visión del patriarcado de esta perspectiva feminista tendrá sesgos esencialistas, universalistas (a-históricos) lo cual en Latinoamérica se constituirá en un problema teórico y político dentro del propio campo del feminismo y en las articulaciones con otros movimientos. Asimismo, las coyunturas políticas centradas en las demandas hacia el Estado, en relación a la pobreza de grandes sectores de la sociedad (lideradas por actores que basan sus análisis únicamente en perspectivas de clase), dificultaran analizar el carácter sexista-patriarcal y étnico de los estados nacionales. Estas situaciones (entre otras, seguramente) provocaron que en Latinoamérica el feminismo se viese como una expresión teórico política que atentaba contra la pretendida "unidad" de las luchas anticapitalistas (ALONSO; DÍAZ, 2012).

Nos interesa inventariar en nuestro acervo las principales líneas del legado de la corriente radical del feminismo para reconceptualizarlas y resituarlas en un contexto geopolítico que María Lugones (2008) caracteriza como "sistema 
moderno/colonial de género". Pensar, como sugiere Lugones, y con anterioridad Crenshaw, las categorías de género y raza separadamente no puede dar cuenta de la violencia contra las "mujeres de color" en el contexto del capitalismo global, ni de las prácticas discursivas institucionales de opresión contra las mujeres indígenas y campesinas. Remarcamos que el capitalismo es un sistema de explotación de clases, que simultáneamente surge generizado, heterosexualizado y racializado.

Para insistir en la complejidad de este campo, nos hacemos eco de las expresiones críticas que comienzan a hacerse oír en la década del 1980 dentro del movimiento feminista. Son las feministas lesbianas, las negras, las chicanas y las asiáticas, entre otras quienes

[...] reclaman la necesidad de atender las complejas relaciones de subordinación a la que se enfrentan mujeres concretas: respondiendo no sólo a las relaciones de género o de clase, sino también al racismo, la lesbofobia, los efectos de la colonización y la descolonización y las migraciones transnacionales (ESKALERA KARACOLA, 2004, p. 10).

Desde el feminismo negro, fundamentalmente en el contexto anglosajón, se denuncian los sesgos racistas del feminismo blanco y la nula referencia a las distintas realidades materiales de mujeres blancas y negras. Mercedes Jabardo (2012, p. 32) plantea:

Mientras el feminismo moderno / ilustrado se desarrolló a partir de Simone de Beauvoir y su afirmación "no se nace mujer. Se llega a serlo", los discursos de género en el feminismo negro parten de una negación, de una exclusión, de un interrogante, el que retoma bell hooks de Sojourner Trhth en uno de los primeros textos del pensamiento feminista negro: "¿Acaso no soy una mujer?".

Desde esta posición, la identidad de mujer es simultáneamente reclamada y reconstruida.

Dado que las críticas del feminismo negro no agotan la multiplicidad de posiciones étnicas, el término "mujeres de color" fue tomando forma como un artefacto teórico y político con miras a agrupar las opresiones comunes en torno al racismo, que experimentan mujeres de distintas procedencias nacionales y étnico-raciales. 
En la tensión y riqueza política de vivir a caballo entre varias culturas, empleando varios idiomas y en la distancia crítica que implica no ser reconocida como adecuada en ninguno de los marcos disponibles, como mujer, lesbiana y chicana, la conciencia mestiza de Anzaldúa surge de las posibilidades de hacer habitable la propia posición de frontera (ESKALERA KARACOLA, 2004, p. 11-12).

El racismo será el epicentro en el que colocan la desigualdad (JABARDO, 2012) y la interseccionalidad de las opresiones, la base conceptual de sus teorizaciones (HILL COLLINS, 2012; JABARDO, 2012).

Las críticas que estos constructos teóricos realizaron, pero también las que recibieron, posibilitaron la articulación de las perspectivas queer que, en ocasiones tensionando perspectivas feministas hegemónicas, muestran las disonancias en la relación hegemónica (de género, raza y clase) entre: cuerpo-géneros-sexualidades.

La praxis queer funcionó sobre la puesta en escena desplazada, exuberante, paródica, de las normas dominantes en materia de sexo, de sexualidad y de color [...] Lo que se pone en escena es tanto el estatus racial como el sexual, haciendo de la feminidad blanca, feminidad dominante y racializada, una verdadera mascarada: reforzándola y desestabilizándola al mismo tiempo como norma de referencia y como ideal (DORLIN, 2008, p. 92-93).

La teoría queer busca problematizar la existencia a priori de un sujeto político para su teoría, y problematiza, como dice Dorlin, al sujeto homosexual como implícitamente gay, blanco y económicamente acomodado. En este sentido, la teoría queer interroga tanto el anudamiento causalístico entre cuerpo-sexo, género y sexualidad, como también el entronque entre sexualidad y racismo. El cuerpo sexuado, no es el basamento natural de las divisiones sociales sino el efecto de relaciones de poder, articulado con la heterosexualidad obligatoria (DORLIN, 2008).

Una de las discusiones que atraviesa a los feminismos, en su calidad de teorías y de discursos políticos, es la existencia o no de un sujeto político colectivo constituido previamente a la acción colectiva. En el terreno político, discursos feministas sostuvieron durante mucho tiempo que las "mujeres" travestis o trans no podían ser feministas porque habían nacido hombres, asumiendo una posición esencialista y biologicista de "policía de lo real” (DORLIN, 2008). 
Nos interesa detenernos en este punto, dado que en el campo educativo, las problematizaciones acerca de las relaciones de género suelen toparse con un "techo de cristal". El límite que encontramos en los discursos que circulan en nuestro medio está puesto en el obstáculo para pensar la heterosexualidad racializada como una institución política, a la heteronormatividad como "[...] la obsesión por normalizar la sexualidad a través de discursos que posicionan (lo extraño) como desviado" (WARNER, apud BRITZMAN, 1995, p. 7) y a la homosexualidad como un escape del deseo a esa norma, a ese orden hegemónicamente instituido (y no como una anormalidad, patología o perversión). Por otra parte, dificultad también para pensar a la heteronormatividad como reguladora de la mirada hacia y sobre los cuerpos. De estos aspectos nos ocuparemos a continuación.

\title{
Las instituciones educativas: policías contra las ambigüedades
}

\begin{abstract}
"El pensar sobre una vida posible es un lujo sólo para aquellos que ya saben que son posibles. Para aquellos que todavía están tratando de convertirse en posibles, esa posibilidad es una necesidad" (Judith Butler).
\end{abstract}

Nos hemos propuesto estudiar las distintas estrategias a través de las cuales se consolida en el día a día de la pedagogía cotidiana la consideración del cuerpo como naturaleza pre discursiva (sin significaciones, sin cultura), perpetuándose la relación un cuerpo, un género, una sexualidad normal; desnudar las operaciones que se articulan constituyendo tanto a esas/os sujetas/ os "que importan", cuyos cuerpos (hegemónicos) resultan inteligibles para el conocimiento hegemónico, como a esos cuerpos otros que, desde su condición de ininteligibles, son paradójicamente necesarios ya que marcan los límites de lo que se considera "normal", pero a la vez pugnan por hacer valer su derecho a formar parte de la cotidianeidad. Adelantémonos a decir que la normalidad es una construcción eurocentrada que operó como matriz de la colonialidad del poder, del saber y del ser.

Saber y poder operan juntos estableciendo una serie de criterios sutiles y explícitos que ordenan el mundo, definiendo lo "aceptable", lo "posible", lo "pensable". Por ello, no sólo es necesario comprender cómo se instituyen los términos que definen el campo de lo inteligible, sino que es preciso "[...] 
localizar la forma en la que el campo se encuentra con su punto de ruptura, los momentos de sus discontinuidades y los lugares donde no logra constituir la inteligibilidad que promete" (BUTLER, 2004, p. 305). Es decir, aquellas zonas en que las categorías del conocimiento hegemónico son puestas en cuestión, disputadas; los momentos donde se muestra su contingencia y su posibilidad de ser transformadas.

Cómo dijimos, vamos a dar cuenta, sintéticamente, de tres instancias en las cuales fuimos dándole densidad al entramado entre teoría y práctica, tomando como eje la insoportable pesadez de la normalidad e interrogándonos acerca de ¿Cómo se la vive, cómo se la interpela, cómo se la rechaza o cómo se la asimila? ¿Qué se tiene - desde la disidencia - para decir a/sobre la normalidad? ¿Cuáles son los significados individuales y colectivos que construyen desde sus cuerpos? ¿Qué saberes disputan al conocimiento hegemónico? ¿Cuáles son sus demandas y reclamos? ¿Cuáles las discriminaciones que denuncian?

\section{A) Por una educación pública antidiscriminatoria, no sexista, no andro-} céntrica, no heterosexista, es el nombre del proyecto de extensión desarrollado entre los años 2007-20104, el cual se convirtió en un importante paraguas para desplegar acciones de formación en espacios institucionales. Tuvo como propósito contribuir a problematizar en la educación pública y en la sociedad de la ciudad de Neuquén la necesidad de abordar colectiva y pedagógicamente problemáticas referidas a las heterogéneas y solapadas discriminaciones por pertenencias a géneros y sexualidades transgresoras, tendiendo a generar prácticas escolares e institucionales no sexistas, no androcéntricas, antidiscriminatorias, antihomo/lesbo/bi/travestofóbicas. Uno de los paradigmas con el que tuvimos que debatir es el de la "tolerancia". En ese sentido, una de las primeras acciones fue distribuir, en las escuelas públicas e instituciones de formación docente, el afiche: "Tolerar es discriminar", allí se busca reflexionar sobre el lugar de privilegio de quien se arroga (individual o colectivamente) la posición de ser tolerante y la negación de historias y subjetividades que esto conlleva.

Con el mismo carácter de interpelación y formación, editamos - en ocasión del 28 de junio de 2010 - un cuadernillo y un CD con materiales teóricos y para el trabajo áulico (cuentos, videos cortos, películas), titulado: "No se nace heterosexual". La inspiración aquí fue proponer efemérides otras para las escuelas públicas. En la escuela pública se conmemoran/festejan/celebran diferentes fechas conocidas como efemérides, la mayor parte de ellas tienen que

4 Del mismo hoy repensaríamos su nombre, tratando de dar cuenta de la manifestación de la discriminación interseccionadamente y la praxis queer en el terreno de sus apariciones institucionales y populares. 
ver con acontecimientos que el Estado Nacional ha instituido para contar una parte de la historia, reproduciendo y recreando cierta memoria colectiva. Esas efemérides, en general, se estructuran desde una visión de la historia donde los protagonistas son varones blancos, burgueses $\mathrm{y}$, por añadidura, considerados heterosexuales. Consideramos que hay otras historias, otros acontecimientos, otras fechas otras/otros/otrxs protagonistas que la educación pública en perspectiva antidiscriminatoria, no androcéntrica, no sexista, no heterosexista, necesita instituir para avanzar en procesos democráticos hacia adentro y hacia afuera de sí misma. En este sentido, nos pareció oportuno tomar el "día del orgullo" como fecha para pensar en efemérides otras.

La tercer producción fue el cuadernillo: "Alerta, pasá la voz: A la escuela le robaron la normalidad" (Noviembre, 2011). Aquí publicamos artículos de reflexión para docentes, abordando el tema de la hetero-normalidad escolar y su problematización a partir de la Ley de Matrimonio Igualitario, sancionada en Argentina el 15 de julio de 2010. También incluimos sugerencia bibliográfica para una educación sexual desde perspectivas de género y amplia bibliografía sobre géneros, cuerpos y sexualidades. Nos interesó trasmitir la idea que la normalidad está en problemas porque un/una estudiante o un/una docente que elige tener pene y tetas hace trastabillar las clasificaciones, confunde, inquieta. No quiere, no puede, permanecer en el closet; no entra en él. Pero, a la vez, sostener que los anormalizadores, al decir de Skliar (2006), seguramente seguirán inventando monstruosidades y closets. La interpelación es: ¿de qué lado nos ponemos?

Además, el proyecto desplegó una cuantiosa serie de jornadas, seminarios $\mathrm{y}$ talleres de formación para docentes y estudiantes ${ }^{5}$. Es de destacar que habiendo culminado en el año $2010 \mathrm{y}$, como parte de sus efectos, hay constantes referencias a los materiales difundidos, los mismos continúan circulando entre docentes, perduran visiblemente afiches en las instituciones y grafitis en paredes con las consignas de las producciones, en una suerte de apropiación pedagógica popular de las interpelaciones lanzadas.

B) Aproximaciones al estudio del movimiento sexo-genérico en Argentina, es el título del proyecto de investigación, realizado entre los años 2006 y 2009. Nos interesa focalizar algunas cuestiones trabajadas con activistas travestis. Haremos referencia especialmente a lo que produjimos a partir de

5 Jornada de intercambio con Marlene Wayar, activista trans, "Discriminación sexo-genérica en educación contra la comunidad travesti"; Seminario-taller "Cuando la escuela piensa las disidencias sexuales y de géneros, se piensa a sí misma", desarrollado en una escuela media, a partir de una convocatoria del equipo directivo, relacionada con la necesidad de acompañamiento ante la presencia de una joven estudiante trans; Seminario “¿Qué nos provocan los géneros y las sexualidades diferentes?”; Seminario Taller "Nadie es normal"; Ciclo de videos por la diversidad de géneros y sexualidades. 
entrevistas en la organización ALITT (Asociación de Lucha por la Identidad Travesti y Transexual). En este grupo encontramos la articulación de estrategias que Nancy Fraser (1997) denomina de reconocimiento y de redistribución; o sea, reconocimiento identitario pero también reclamo por transformaciones políticas y económicas y de justicia distributiva. Los puntos centrales a los que llegamos en este trabajo son:

- Resignificar el término travesti fue una de las primeras acciones que concentró al grupo de travestis agrupadas - ALITT. Utilizado hegemónicamente como sinónimo de lo perverso, patológico, monstruoso, indeseable y desviado en extremo, intentarán gestar nuevos sentidos políticos para esa designación buscando alejarse de las heterodesignaciones impuestas. La apuesta es vincular el término travesti a la lucha, la resistencia y el derecho a ser portadoras de carta de ciudadanía y así auto-afirmarse y auto-designarse.

- Otro aspecto a destacar es el accionar político encaminado a generar discursos sobre una ciudadanía travesti, lo hacen mediante la desregulación de ciertos pactos de significación. El ejercicio de la ciudadanía implica necesariamente la posibilidad de espacios. El espacio público para las travestis está sobredeterminado por la prostitución como forma - casi excluyente - de sobrevivencia. En la lucha por una ciudadanía sexual y genérica plena, una condición objetiva y subjetiva a deconstruir es la relación directa que - en Argentina y en toda Latinoamérica - anuda travestismo a prostitución.

- En este punto necesitamos hacer una referencia obligada, que nos resulta clave para comprender el recurso a la prostitución como salida casi exclusiva para asegurarse el sustento y la sobrevivencia: la expulsión de las travestis del sistema educativo. Las circunstancias hostiles que sellan la experiencia de escolarización de la mayoría de las niñas y adolescentes travestis, condicionan drásticamente sus posibilidades en términos de inclusión social y de acceso a empleos de calidad.

La principal estrategia que utiliza la escuela para dificultar el tránsito hacia una ciudadanía plena es la imposición de lo que dimos en llamar: edictos contravencionales escolares. Esto se expresa a través de un complejo entretejido de violencia simbólica y de violencia física. En las entrevistas realizadas con activistas de algunos de grupos travestis de la ciudad de Buenos Aires, la mención a la escuela, a la educación institucionalizada, es reiterada. Forma parte de las críticas y de los deseos, de las deudas consigo mismas y de los recuerdos dolorosos. Una de quienes logró terminar la escuela media, se llama así misma: la travita intelectual. 
Ciertamente los mandatos, prejuicios, estereotipos, conforman buena parte del clima escolar y de las experiencias de discriminación vividas. Pero también hay agenciamientos ${ }^{6}$, hay fugas. Consideramos que la elaboración de estrategias es, para las referentes de las organizaciones entrevistadas, un punto clave en su práctica política. Por ejemplo, sostiene Lohana Berkins (2006, p. 80): “[...] Cuando nosotras nos empoderamos a través de la palabra, nos empoderamos con el cuerpo, a través de las organizaciones, y empezamos a ser corpóreas dentro de la sociedad, empezamos a tener voz pública."

Del material de campo analizado, podemos dar cuenta de tres estrategias de fuga / resistencia por parte de estas militantes que aportan al desarrollo de reflexiones pedagógicas en un sentido que debate con (contra) la lógica normalizadora:

- reafirmar el cuerpo / identidad como punto de partida de los aprendizajes;

- revalorizar la experiencia y saberes del colectivo;

- afirmar la imperiosa necesidad de trabajo digno y su relación con lo educativo.

Al igual que en el proyecto anteriormente expuesto, el círculo entre cultura-educación-trabajo, cuando es sostenido sobre la "normalidad" genérica, sexual, racial y clasista de los cuerpos, se hace incompatible con los preceptos de igualdad de la escuela moderna. La diferencia se traduce en desigualdad, a través del invento (entre otros) de la normalidad. La diferencia que "turba el orden cultural" (al decir de Mary Douglas) es justamente "no encajar" en alguna categoría. Lo importante de todo esto es saber si las instituciones educativas pueden al menos mantenerse en la tensión entre normalidad y ambigüedad y no seguir inclinándose hacia la lógica heternormativa, como si no tuviesen ninguna otra opción.

C) Entrar enterxs a las instituciones educativas. Argentina cuenta desde el 9 de mayo de 2012 con la Ley de Identidad de Género (Ley 26.743), pero obviamente sujetxs trans circulan por los espacios educativos, desde antes de que la ley les garantizara derechos básicos. Dando cuenta de experiencias localizadas, diremos que anterior a esta ley, a instancias de dos estudiantes trans, acompañadxs por dos organizaciones: Diversidad Alto Valle y la Colectiva Feminista La Revuelta, presentamos al Consejo Superior de la Universidad del Comahue un

6 Utilizamos esta expresión en el sentido en que Mahmood conceptualiza la agencia social, no como sinónimo de resistencia en las relaciones de dominación sino como una capacidad de acción que se habilita y crea en relaciones de subordinación históricamente específicas. Argumenta sobre el obstáculo de situarse en el binomio resistencia/subordinación, porque, dice, no presta suficiente atención a las motivaciones, deseos y objetivos de grupos particulares (en el caso de su investigación, a las mujeres islámicas con prácticas religiosas) (MAHMOOD, 2008, p. 183). 
proyecto de ordenanza para que se respete la identidad de género autopercibida en todas las dependencias académicas. Como sostiene Silvia Duchasky (2007, p. 89):

Hay momentos en las vidas sociales y de las instituciones en los que el presente, el momento o el instante adquieren relieves insospechados. Lejos de ser porciones preparatorias del futuro, fragmentos de un tiempo lineal o componentes de un plan general, pueden ser la ocasión para desplegar una potencia, abrir una clausura o ensanchar una experiencia.

La ordenanza se aprobó en el mes de octubre del 2010. Consta de tres artículos que centralmente establecen:

[...] se hará constar en la libreta universitaria, los padrones electorales, trámites internos, citaciones, memorandos, registros, listados, notas, actas, pre-actas, constancias de asistencia, partes, entre otros, el nombre autopercibido o identitario del/la estudiante, trabajador/a docente o no docente que así lo requiera. [...] En aquellas circunstancias en las que la persona sea nombrada en público, $[\ldots]$ se deberá utilizar únicamente el nombre de elección que respete la identidad de género adoptada, y no el nombre obrante en el documento de identidad (UNIVERSIDAD DEL COMAHUE, 2010).

Como decíamos, en 2012 se aprueba la Ley 26.743, sin embargo no deja de ser importante que la universidad cuente con esta ordenanza, dado que todavía ninguna de las dos normativas se conoce lo suficiente y hay mucho trabajo pedagógico por realizar.

Con relación a la Ley Nacional de Identidad de Género, digamos que llegar a su sanción resulta de un sostenido e incansable activismo de diversos movimientos socio sexuales que instalan sus demandas en la escena pública; en los años 1990 se expresaron con especial fuerza grupos de travestis y trans para denunciar las inferiorizaciones, estigmatizaciones, marginalizaciones, discriminaciones y exclusiones a las que se ven sometidas. La transformación de estos reclamos en el reconocimiento de derechos se inscribe en un proceso más vasto de consecución de derechos vinculados a regulaciones sexuales y de género 7 .

7 Entre ellas, la Ley de Matrimonio Igualitario (2010), la Ley para Sancionar, Prevenir y Erradicar las Violencias contra las Mujeres en todos los ámbitos donde desarrolle sus relaciones interpersonales (2009), la Ley de Educación Sexual Integral (2006), la Ley de Salud Sexual y Procreación Responsable (2004). 
El articulado de la Ley de Identidad de Género implica un acto simbólico de gran alcance. Involucra - al menos - cuatro operaciones discursivas y materiales concretas: la des-judicialización (el reconocimiento identitario es un trámite personal sencillo en oficinas del Registro Civil de las Personas), la des-estigmatización (en tanto se penaliza la discriminación, la des-criminalización (el Estado reconoce la libertad de cada persona a manifestar su género de acuerdo a su sentir personalísimo) y la des-patologización (no requiere la asunción de ninguna enfermedad para las garantías efectivas de los derechos contemplados en la Ley).

Vale remarcar que las leyes son condición necesaria pero insuficiente para lograr el ingreso al estatus de vida humana digna de ser vivida. Como otras, la Ley de Identidad de Género constituye un piso de posibilidades que deberá ser acompañada de políticas públicas concretas, para lograr disminuir las brechas estructurales de desigualdad a la que este colectivo se ve - aún hoy - expuesto. El reclamo por la real inclusión en el sistema educativo y en el mundo del trabajo sigue presente.

Para finalizar este apartado nos interesa destacar brevemente intervenciones realizadas en ámbitos terciarios de formación docente. En todo el país, se impulsó, a partir de la sanción de la Ley Nacional de Educación (2006), una transformación curricular que extendió a 4 años la formación docente para el nivel primario e inicial. En la provincia de Neuquén, trabajadoras y trabajadores de la educación de los Institutos Superiores de Formación Docente (ISFD) nos nucleamos para imponer a las autoridades gubernamentales condiciones democráticas y participativas dentro de esos debates abiertos. Las perspectivas epistemológicas y políticas que se plasman en el nuevo documento curricular, aprobado en el año 2009 y vigente para toda la provincia, son deudoras de las pedagogías críticas, incorporan los enfoques multiculturales y de género. Luego de intensas discusiones, disputas y negociaciones, esta inclusión se acuerda tanto de manera transversal para el conjunto de espacios curriculares como en la creación de espacios específicos concretados en seminarios obligatorios.

En abril de 2013, desplegamos en el ISFD n. ${ }^{\circ} 12$ el Primer Foro de Estudiantes y Profesorxs de Formación Docente sobre sexualidades, géneros, feminismos y espacios pedagógicos. El evento se promueve desde el dictado del Seminario "Derechos Humanos: Educación Sexual Integral y Relaciones de Género", para ser organizado junto a estudiantes y una decena de profesoras interesadas en la temática. Los propósitos esgrimidos en la convocatoria fueron: a) Promover la creación de un espacio de encuentro que colabore en la construcción de argumentos sobre la importancia de reparar en la presencia ineludible de los cuerpos generificados y sexualizados en el día a día escolar; b) Generar un espacio de reflexión e intercambio sobre las pedagogías de género y sexua- 
lidad presentes en las instituciones educativas para provocar miradas y sentidos desnaturalizadores de las normalidades presentes y c) Propiciar la socialización de experiencias de trabajo, programas de estudios, recursos pedagógicos y didácticos para coadyuvar en la construcción de propuestas de enseñanza-aprendizaje y des-aprendizaje desde perspectivas antidiscriminatorias.

Éstas y otras numerosas instancias de diálogos, conversaciones, encuentros fueron posibilitando la elaboración de cierta forma de pensamiento colectivo proyectivo capaz de acoger la creación del espacio Habitar-Sex (Consejería en Derechos Sexuales y Reproductivos) inaugurado en el mismo ISFD n. ${ }^{\circ} 12$, en julio de 2013. En el documento de fundamentación escribimos:

[...] nos proponemos escuchar, orientar, intervenir y articular un trabajo vinculado a los derechos sexuales y a los derechos reproductivos de las y los estudiantes, quienes al igual que profesoras y profesores estamos siendo sujetxs de género y de sexualidad. Su creación y puesta en marcha surge de la mano de las heterogéneas experiencias que relatan estudiantxs que transitan por el ISFD y que, muchas veces, se tornan decisivas en relación a la continuidad o no de su carrera formativa, interpelando de manera diversa a la institución (HABITAR-SEX, 2010).

\section{Habilitar apuestas por acoger los desbordes pedagógicos (sin pretensión de cierre)}

Desde los feminismos y las teorías queer, incluyendo las producciones pedagógicas ${ }^{8}$, vemos como la desestabilización de la construcción hegemónica: dos cuerpos, dos géneros, una sexualidad normal, posibilita la apertura de interrogantes, de praxis intelectuales y políticas y de desafíos para el colectivo docente. Esto requiere la sistemática revisión de la imprenta nacionalista de los discursos y prácticas escolares, para aprender cómo la "invención de la heterosexualidad" se corresponde con la organización material y simbólica de los estados y de los espacios pedagógicos. Asimismo, es importante realizar

8 "El punto de partida de este encuentro entre lo queer y la pedagogía podría situarse en una reflexión que Spivak hace: debemos pensar sobre la forma en que la educación institucional o conjunto de discursos y prácticas se encuentra relacionada con la autodeterminación de las poblaciones subalternas del mundo, así como de su subordinación" (SPIVAK, 1992, apud PLANELLA; PIE, 2012). 
algunas observaciones a perspectivas feministas y de la pedagogía crítica, de las que hay que hacer relecturas situadas.

El dislocamiento del cuerpo natural, asiento y efecto de las ideas de normalidad, pero también de agenciamientos, sigue siendo una disputa pedagógica, disputa por los cuerpos, disputa por conseguir que las corporalidades transformadas habiten dignamente las instituciones educativas.

De todas formas no podemos dejar de preguntarnos, si los cuerpos de la travestis - cuya radicalidad de la diferencia corporal interpela las certezas de las pedagogías normalizadoras - pueden atraer a pedagogas y pedagogos a implicarse en la deconstrucción de los binarismos de género, sexo y sexualidad. Este interrogante dispara otros: ¿Es posible que se asuman proyectos educativos capaces de rechazar y desestabilizar la "normalidad exorbitante" y que se proponga volver una y otra vez sobre los fundamentos de la misma? ¿Puede pensarse una pedagogía otra capaz de huir de las instrucciones pedagógicas normalizadoras y heteronormalizadoras? ¿Es posible proyectar la construcción de un nuevo imaginario político y ético en el que la ruptura de las lógicas binarias no signifique nuevas formas de control bajo la forma de pedagogías de la tolerancia, el respeto y la integración?

Consideramos que las acciones enunciadas contribuyen, desde la escucha de quienes están en los movimientos de reclamo y nuestro estar militantemente en las instituciones de formación, a desbordar la "normalidad exorbitante".

La apuesta de Deborah Britzman con su pedagogía transgresora permite la construcción de zonas alternativas de identificación y crítica " [...] necesarias para que el pensamiento sea consciente de sus estructuras dominantes, y para que se creen nuevos deseos" (BRITZMAN, 2002, p. 200).

Salirse de los cánones que promueven la pedagogía de la "normalidad exorbitante" requiere también sacudir los propios cuerpos de quienes enseñamos, en tanto los conocimientos están encarnados corporal y subjetivamente; abrirse a considerar los saberes de lxs sujetxs sobre aquello que les pasa proponiéndonos desarrollar una razón imaginativa (al decir de MÉLICH, 2010) capaz de crear otras epistemologías que generen significaciones desestabilizadoras de las normalidades corporales y las heternormatividades colonizadoras; construir espacios áulicos flexibles y audaces que hagan habitar las contingencias, los acontecimientos, las incertidumbres y las ambigüedades. Transformar las peda-

9 Britzman (1998, 2002, p. 208) utiliza esta expresión para dar cuenta que “[...] ‘el otro’ es representado bien como ininteligible, bien como algo inteligible únicamente en un caso especial y, en consecuencia, nunca como alguien a quien le está autorizado formar parte del día a día. La normalidad exorbitante se construye en el momento en que se representa al otro como un espacio de desviación y dolencia y, por lo tanto, como si fuera necesario contenerlo". 
gogías habilitando los desbordes, dando cabida a las revueltas pedagógicas que nos hagan más felices las existencias en las aulas y en la vida toda.

\section{REFERENCIAS}

ALONSO, Graiela; DÍAZ, Raúl. Reflexiones acerca de los aportes de las epistemologías feministas y descoloniales para pensar la investigación social. Debates urgentes, Buenos Aires, v. 1, n. 1, p. 75-98, Junio 2012.

BERKINS, Lohana; KOROL, Claudia (Comp.). Diálogo. Prostitución / Trabajo sexual: Las protagonistas hablan. Buenos Aires: Feminaria Editora, 2006.

BRITZMAN, Deborah. ¿Qué es esa cosa llamada amor? Taboo: The Journal of Culture and Education, v. 1, p. 1-18, Primavera 1995. Traducción de circulación interna Prof. ${ }^{\mathrm{a}}$ Gabriela Herczeg.

. La Pedagogía transgresora y sus extrañas técnicas (1998). En: MÉRIDA, Rafael. Sexualidades transgresoras. Una antología de estudios queer. Barcelona: Icaria, 2002. p. 197-228.

BUTLER, Judith. Deshacer el género. Barcelona: Paidós, 2004.

DORLIN, Elsa. Sexo, género y sexualidades. Introducción a la teoría feminista. Buenos Aires: Nueva Visión, 2008.

DUCHASKY, Silvia. Maestros errantes. Buenos Aires: Paidós, 2007.

ESKALERA KARACOLA. Prólogo. En: Otras inapropiables. Madrid: Traficantes de sueños - mapas, 2004. p. 9-32.

FRASER, Nancy. Iustitia Interrupta. Reflexiones críticas desde la posición postsocialista. Bogotá: Siglo del Hombre Editores: Universidad de los Andes, 1997.

HABITAR-SEX. Consejería en Derechos Sexuales y Reproductivo, 2010.

HILL COLLINS, Patricia. Rasgos distintivos del pensamiento feminista negro. En: JABARDO, Mercedes (Ed.). Feminismos negros. Una antología. Madrid: Traficantes de sueños - mapas, 2012. p. 99-134.

JABARDO, Mercedes. Introducción Construyendo puentes en diálogo desde / con el feminismo negro. En:___ (Ed.). Feminismos negros. Una antología. Madrid: Traficantes de sueños - mapas, 2012. p. 27-56.

LUGONES, María C. Colonialidad y género: hacia un feminismo descolonial. En: MIGNOLO, Walter (Comp.). Género y descolonialidad. Buenos Aires: Ediciones del Signo, 2008. p. 13-54. 
MAHMOOD, Saba. Teoría feminista y el agente dócil: algunas reflexiones sobre el renacimiento islámico en Egipto. En: SUÁREZ NAVAZ, Liliana; HERNÁNDEZ CASTILLO, Rosalba (Ed.). Descolonizando el feminismo. Teorías y prácticas desde los márgenes. Madrid: Cátedra, 2008. p. 162-214.

MÉLICH, Joan-Carles. Transformaciones. Tres ensaios de filosofia e da la educación. Buenos Aires: Miño y Dávila, 2010.

PLANELLA, Jordi; PIE, Asun. Pedagoqueer: Resistencias y subversiones educativas. Educación XXI, Barcelona, v. 15.1, p. 265-283, 2012.

PULEO, Alicia. Lo personal es político: el surgimiento del feminismo radical. En: AMORÓS, Celia; DE MIGUEL, Ana (Ed.). Teoría feminista: de la Ilustración a la globalización 2. 2. ed. Madrid: Minerva Ediciones, 2007. p. 35-67.

SKLIAR, Carlos. Palabras de la normalidad. Imágenes de la anormalidad. En: DUSSEL, Inés; GUTIÉRREZ, Daniela (Comp.). Educar la mirada. Políticas y pedagogías de la imagen. Buenos Aires: Manantial - FLACSO, 2006. p. 189-197.

UNIVERSIDAD DEL COMAHUE. Consejo Superior. Ordenanza para que se respete la identidad de género autopercebida em todas las dependencias académicas, 2010.

Texto recebido em 09 de maio de 2014.

Texto aprovado em 19 de maio de 2014. 